\title{
Therapeutic effects of adenoviral gene transfer of bone morphogenic protein-7 on a corneal alkali injury model in mice
}

\author{
Shizuya Saika ${ }^{1}$, Kazuo Ikeda ${ }^{2}$, Osamu Yamanaka ${ }^{1}$, Kathleen C Flanders ${ }^{3}$, Yuji Nakajima ${ }^{2}$, \\ Takeshi Miyamoto $^{1}$, Yoshitaka Ohnishi ${ }^{1}$, Winston W-Y Kao ${ }^{4}$, Yasuteru Muragaki ${ }^{5}$ and \\ Akira Ooshima ${ }^{5}$ \\ ${ }^{1}$ Department of Ophthalmology, Wakayama Medical University, Kimiidera, Wakayama, Japan; ${ }^{2}$ Department \\ of Anatomy, Graduate School of Medicine, Osaka City University, Asahimachi, Abeno, Osaka, Japan; \\ ${ }^{3}$ Laboratory of Cell Regulation and Carcinogenesis, National Cancer Institute, National Institutes of Health, \\ Bethesda, MD, USA; ${ }^{4}$ Department of Ophthalmology, University of Cincinnati Medical Center, Cincinnati, \\ OH, USA and ${ }^{5}$ Department of Pathology, Wakayama Medical University, Kimiidera, Wakayama, Japan
}

\begin{abstract}
An alkali burn in the cornea is a common serious clinical problem often leading to permanent visual impairment. Since transforming growth factor- $\beta$ (TGF- $\beta$ ) is involved in the response to corneal injury, we evaluated the therapeutic effects of adenoviral gene transfer of mouse bone morphogenic proten-7 (BMP-7), which has antagonistic effects on TGF- $\beta$ in tissue fibrosis. Burned cornea did not express endogenous BMP-7 mRNA and protein. Resurfacing of the burned cornea by invading conjunctival epithelium was accelerated by adenoviral introduction of BMP-7. Exogenous BMP-7 expression also suppressed myofibroblast generation, appearance of monocytes/macrophages and expression of MCP-1, TGF- $\beta$ s, and collagen I $\alpha 2$ chain in the affected stroma. Ectopic BMP-7 did not suppress stromal neovascularization throughout the interval studied and also did not reduce VEGF mRNA expression at Day 10. Ectopic BMP-7 in burned corneal tissue resulted in activation of Smad1/5/8 signaling and partial suppression of the phospho-Smad2 signal. These data suggest that overexpression of BMP-7 is an effective strategy for treatment of ocular alkali burns.
\end{abstract}

Laboratory Investigation (2005) 85, 474-486, advance online publication, 7 February 2005; doi:10.1038/labinvest.3700247

Keywords: bone morphogenic protein-7; gene therapy; adenovirus; cornea; alkali burn; wound healing; mouse

The cornea is a highly organized avascular transparent tissue of the eye that must remain transparent to refract light properly. An alkali burn to the cornea is a serious problem that may cause severe and permanent visual impairment. ${ }^{1}$ Influx of inflammatory cells such as monocytes/macrophages, activation of corneal cells, that is, keratocytes (corneal fibroblasts) and epithelial cells, and subsequent stromal neovascularization are all involved in the postalkali tissue damage in the cornea. ${ }^{2,3}$ Although the basement membrane is resistant to exposure to alkali, its degradation by matrix metalloproteinases (MMPs, gelatinases) secreted by damaged cells contributes to the pathogenic ulceration and perforation of the stroma. ${ }^{4-7}$ Activation of keratocytes

Correspondence: Professor S Saika, MD, PhD, Department of Ophthalmology, Wakayama Medical University, 811-1 Kimiidera, Wakayama 641-0012, Japan.

E-mail: shizuya@wakayama-med.ac.jp

Received 08 November 2004; revised 20 December 2004; accepted 21 December 2004; published online 7 February 2005 results in the generation of myofibroblasts, and increases the contractile characteristic and extracellular matrix production of these cells. Surgical transplantation of autografts or allografts of limbal epithelium containing corneal epithelial stem cells in association with long-term use of immunosuppressive drugs is used in some cases. ${ }^{8,9}$ Moreover, even this treatment is not effective in severe cases, leading to loss of vision, and emphasizing the need for development of new, more effective, treatment strategies.

A number of growth factors and cytokines are believed to be involved in the tissue destruction and late scarring that occur in the cornea postalkali burn. Two essential components are a group of inflammatory cytokines that signals through nuclear factorkappa B $(\mathrm{NF}-\kappa \mathrm{B})$, the main signaling pathway mediating inflammatory responses ${ }^{10,11}$ and transforming growth factor- $\beta$ (TGF- $\beta$ ), one of the most important growth factors regulating tissue fibrosis and inflammation. TGF- $\beta$ modulates behaviors of several corneal cell types, that is, epithelial cell 
migration and proliferation and transdifferentiation of keratocytes to myofibroblasts, and also is chemotactic to monocytes/macrophages during wound healing in the cornea as in other tissues. ${ }^{12-14}$ Blocking signaling mediated by Smad2/3, the cytoplasmic signaling intermediates specific for TGF- $\beta$ / activin, is effective in inhibiting injury-induced tissue fibrosis in many tissues, such as skin, kidney, and the lens and retina of the eye. ${ }^{15-26}$ We have recently revealed that both topical administration of SN50, an inhibitor of NF- $\kappa$ B signal, and adenoviral gene introduction of the Smad7, an inhibitory Smad that blocks Smads2/3, block tissue destruction in an alkali-burned cornea in mice (Saika et al, 2004 ${ }^{24,35}$ ).

Hepatocyte growth factor ${ }^{27,28}$ and bone morphogenic protein-7 (BMP-7) ${ }^{29-32}$ are cytokines that antagonize TGF- $\beta$ activity in tissue fibrosis. BMP-7 utilizes Smad1/5/8 signaling which counteracts TGF- $\beta /$ Smad signaling by, in part, upregulation of inhibitors of differentiation 2 and 3 (Id2 and Id3) ${ }^{33,34}$ It has been reported that BMP-7 attenuates tissue fibrosis in the kidney, ${ }^{29-32}$ and thus we hypothesized that exogenous BMP-7 might suppress tissue fibrosis and inflammation in the cornea after alkali burn. To test this hypothesis, we used a mouse model of total ocular surface burn in which the eye is exposed to sodium hydroxide. Here we show for the first time the therapeutic efficacy of BMP-7 adenoviral-mediated cDNA transfer to the alkaliburned mouse cornea. Evaluation of epithelial healing, stromal repair, influx of inflammatory cells, and patterns of cytokine expression all suggest that gene transfer of BMP-7 improves the healing of the injured tissue and reduces scarring.

\section{Materials and methods}

All the experimental procedures were approved by both the DNA Recombination Experiment Committee and the Animal Care and Use Committee of Wakayama Medical University, Wakayama, Japan, and conducted in accordance with the Association for Research in Vision and Ophthalmology Statement for the Use of Animals in Ophthalmic and Vision Research.

\section{Adenovirus Vector Construction and Virus Purification}

We used the Adenovirus Cre/LoxP-Regulated Expression Vector Set (\#6151, Takara, Tokyo, Japan) to generate recombinant adenovirus as previously reported. ${ }^{35}$ Cosmid pAxCALNLmBMP-7 was constructed by the insertion of mouse BMP-7 cDNA into the SwaI cloning site of pAxCALNLw. ${ }^{36}$ By the COS-TPC method, ${ }^{37}$ recombinant adenovirus of AxCALNLmBMP-7 was generated by transfecting 293 cells with the pAxCALNLSmad7. AxCANCre was generated by transfecting 293 cells with Ax-CALNLCreDNA-TPC as described in the manu- facturer's protocol. The titer of recombinant adenoviruses was measured by the $50 \%$ tissue culture infectious dose method. ${ }^{38}$ Each adenovector was used at the concentration of $2 \times 10^{7} \mathrm{PFU} / \mu \mathrm{l}$. When these two viral vectors coinfect cells, Cre recombinase expressed under the CAG promoter (cytomegalovirus enhancer, chicken $\beta$-actin promoter plus a part of $3^{\prime}$ untranslated region of rabbit $\beta$-globin) activates the stuffer PolyA through the Cre/LoxP system.

\section{Alkali Burn in C57BL/6 Mice and its Treatment with BMP-7 Gene Transfer}

In all, $3 \mu$ l of $1 \mathrm{~N}$ sodium hydroxide solution was applied to the right eye of adult C57BL/6 mice to produce an ocular surface alkali burn under both general and topical anesthesia. ${ }^{39}$ The efficiency of gene transfer by the Cre/LoxP adenoviral vector system was evaluated by coinfection of adenoviruses carrying Cre under control of the CAG promoter or green fluorescein protein (GFP) under control of the LNL promoter. Cre recombinase expressed via the CAG promoter activates the stuffer PolyA through the Cre/LoxP system. Expression of GFP was evaluated in unfixed cryosections using fluorescence microscopy. Moreover, expression of exogenous BMP-7 gene and protein was evaluated by reverse transcription-polymerase chain reaction (RT-PCR) and immunohistochemistry.

The same alkali burn was produced in the right eye of adult C57BL/6 mice $(n=77)$. A mixture $(3 \mu \mathrm{l})$ of recombinant adenoviruses carrying CAG promoter-driven Cre (Cre-Ad) and mouse BMP-7 cDNA was topically administered to the burned cornea at 2 and $24 \mathrm{~h}$, Days 5, 10, 15 after an alkali exposure (BMP-7-Ad group). Our preliminary experiments showed that there was no obvious difference in the histology or healing at the macroscopic level of an alkali-burned mouse eye receiving either Cre-Ad or no application of adenovirus (no vector group), and thus we used corneas of Cre-Ad group as controls. After the evaluation of the corneal surface, the eye globe was enucleated $2 \mathrm{~h}$ after labeling with bromodeoxyuridine $(B r d U)^{40}$ and processed for histological examination in either paraffin sections or cryosections at Day 5, 10, and 20. The number of eyes for paraffin sections were 10 and 10 (Day 5), 9 and 12 (Day 10), or 12 and 12 (Day 20) in the Cre-Ad and BMP-7-Ad groups, respectively. The number of eyes for cryosections were two in each experimental condition.

\section{Immunohistochemistry}

Deparaffinized sections ( $5 \mu \mathrm{m}$ thick) or cryosections (7 $\mu \mathrm{m}$ thick) fixed in cold acetone for $5 \mathrm{~min}$ were processed for indirect immunohistochemistry. The following antibodies were used: rabbit polyclonal anti-phosphorylated Smad2 antibody (1:100 dilution 
in phosphate-buffered saline (PBS), Chemicon, Temecula, CA, USA), goat polyclonal anti-Smad1/ 5/8 antibody (1:100 in PBS, Santa Cruz Biotechnology, Santa Cruz, CA, USA), rabbit polyclonal antikeratin 12 antibody $^{41,42}(1 \mu \mathrm{g} / \mathrm{ml}$ in PBS $)$, mouse monoclonal anti- $\alpha$ SMA antibody (1:100 dilution in PBS, Neomarker, Fremont, CA, USA), goat polyclonal anti-type IV collagen antibody (1:100 in PBS, Southern Biotechnology, Birmingham, AL, USA), and rat monoclonal anti-CD31 (PECAM) antibody (1:100 in PBS, Santa Cruz). Immunohistochemistry for TGF- $\beta 1-3$ was performed as previously reported. ${ }^{43,44}$ Cell proliferation in healing epithelium was determined by immunostaining with anti-BrdU antibody (1:11 in PBS, Roche Diagnostics, Mannheim, Germany) as previously reported $^{40}$ and by determining the number of labeled cells in whole healing epithelia in the affected cornea. Specimens were treated with $2 \mathrm{~N}$ HCl for $60 \mathrm{~min}$ at $37^{\circ} \mathrm{C}$ prior to antibody application. Presence of monocytes/macrophages was examined by using rat monoclonal F4/80 antimacrophage antigen antibody (Clone A3-1, 1:400 dilution in PBS, BMA Biomedicals, August, Switzerland). The number of labeled cells in the central cornea (200 $\mu \mathrm{m}$ length) was determined in four corneas in each condition.

\section{Expression of mRNAs of TGF- $\beta 1$, MCP-1, VEGF, MMP-9 and Collagen $I \alpha 2$ Chain in Burned Corneas by Using Real-Time RT-PCR}

In all, $3 \mu \mathrm{l}$ of $1 \mathrm{~N}$ sodium hydroxide solution was applied to the right eye of adult C57BL/6 mice $(n=28)$ to produce an ocular surface alkali burn and treated as described above (Cre-Ad and BMP-7-Ad groups). Corneas from four mice were obtained from each treatment group at Day 5, 10, or 20 and stored at $-80^{\circ} \mathrm{C}$ degree until extraction of mRNA. Untreated corneas of three C57BL/6 mice were also included to obtain the baseline mRNA expression. Real-time RT-PCR for mRNAs of mouse TGF- $\beta 1$, MCP-1, MMP-9, and VEGF was carried out at Days 10 and 20 and that for collagen I $\alpha 2$ was performed at Days 5, 10, and 20. The real-time RT-PCR method using the Taqman One-Step RT-PCR Master Mix Reagents Kit and the Applied Biosystems Prism 7700 (P-E Applied Biosystems, Foster City, CA, USA) was employed. Primers and oligonucleotide probes were designed according to the cDNA sequences in the GeneBank database, using the Primers Express software (P-E Applied Biosystems) and are listed in Table 1. The RT-PCR conditions were as follows: $2 \mathrm{~min}$ at $50^{\circ} \mathrm{C}$ (stage 1 , reverse transcription), $10 \mathrm{~min}$ at $95^{\circ} \mathrm{C}$ (stage 2, reverse transcription inactivation and AmpliTaq Gold activation), and then 40 cycles of amplification for $15 \mathrm{~s}$ at $95^{\circ} \mathrm{C}$ and $1 \mathrm{~min}$ at $60^{\circ} \mathrm{C}$ (stage 3 , polymerase chain reaction). Levels of expression are presented as relative to those found in an uninjured cornea.
Table 1 Sequence of each primer and probe

\begin{tabular}{ll}
\hline Transcript & Sequence \\
\hline mTGF-b1 & F: $5^{\prime}$-gca aca tgt gga act cta cca gaa-3' \\
& R: $5^{\prime}$-gac gtc aaa aga cag cca ctc-3' \\
& P: $5^{\prime}$-acc ttg gta acc ggc tgc tga ccc-3' \\
& F: $5^{\prime}$-tgg ctc agc cag atg cag t-3' \\
mMCP1 & R: $5^{\prime}$-cca gcc tac tca ttg gga tca-3' \\
& P: $5^{\prime}$-ccc cac tca cct gct gct act cat tca-3' \\
& F: $5^{\prime}$-agc gga gaa agc att tgt ttg-3' \\
mVEGF & R: $5^{\prime}$-caa cgc gag tct gtg ttt ttg-3' \\
& P: $5^{\prime}$-cca aga tcc gca gac gtg taa atg ttc c-3' \\
& F: $5^{\prime}$-aga cca agg gta cag cct gtt c-3' \\
mMMP9 & R: $5^{\prime}$-ggc acg ctg gaa tga tct aag-3' \\
& P: $5^{\prime}$-cgc acg agt tcg gcc atg cac-3'
\end{tabular}

F, forward primer; R, reverse primer; P, probe.

\section{Results}

\section{Efficiency of Viral Gene Transfer into a Burned Mouse} Cornea

In the total ocular surface alkali burn model employed in the present study, GFP expression was seen in conjunctival epithelium, subconjunctival fibroblasts, keratocytes, and healing conjunctival epithelium on the burned cornea similar to our previous observation (Saika et al, data in submission 2004). When the vector was applied to an uninjured mouse cornea GFP was not detected in the epithelium and keratocytes and was evident only in conjunctival epithelium (data not shown) as previously reported..$^{45}$

A mixture of Cre-Ad and a recombinant adenovirus carrying mouse BMP-7 cDNA under control of the Cre/LoxP system was administered at 2 and $24 \mathrm{~h}$, Days 5, 10, 15 after alkali exposure (BMP-7-Ad). Cre recombinase expressed via the CAG promoter activates the stuffer PolyA through the Cre/LoxP system, leading to expression of BMP-7. RT-PCR detected BMP-7 mRNA in BMP-7-Ad-treated corneas, but not in control corneas treated only with Cre-Ad (Figure 1A, at Day 5). Immunohistochemical analysis confirmed ectopic BMP-7 gene transfer effectively resulted in protein expression in epithelium and corneal stroma (Figure 1B(b), at Day 5). In contrast, in corneas of the control group treated with Cre-Ad alone, almost no immunoreactivity for BMP-7 was detected in the cornea (Figure 1B(a)).

\section{Alkali-Burned Corneas Treated with Adenoviral Gene Transfer of BMP-7 Show Improved Healing}

Since preliminary experiments showed no obvious differences in either the histology or the rate of healing of alkali-burned mouse corneas treated with either Cre-Ad alone or no vector, we used corneas of the Cre-Ad group as controls. Healing of the corneal 
A

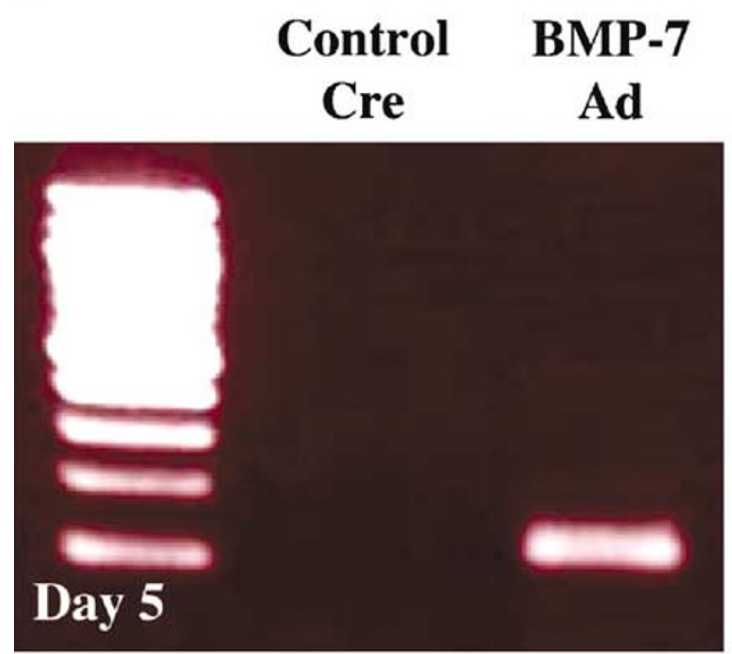

B
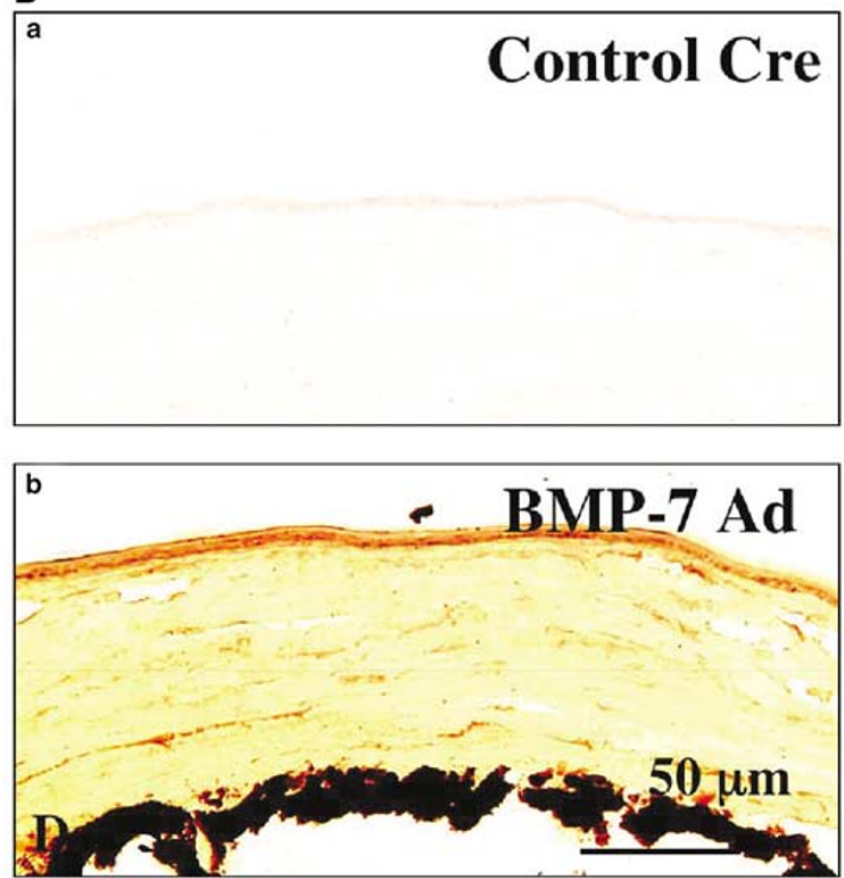

Figure 1 Detection of adenovirally introduced bone morphogenic protein-7 (BMP-7) in healing mouse cornea postalkali burn at Day 5. (A) RT-PCR detects BMP-7 in a cornea treated with coinfection of Cre-adenovirus and BMP-7-adenovirus (hereafter referred as BMP-7 Ad), while no BMP-7 mRNA was detected in a specimens treated with only Cre-adenovirus (Control Cre). (B) Immunohistochemistry also detects BMP-7 protein in regenerated epithelium and burned stroma of a cornea treated with coinfection of Cre-adenovirus and BMP-7adenovirus (BMP-7 Ad, b), while no BMP-7 protein was detected in a specimens treated with Cre-adenovirus (Control Cre, a). Bar, $50 \mu$ m.

surface was evaluated by the presence or absence of an epithelial defect/ulceration (Figure 2A), and the degree of corneal stromal opacification as evaluated macroscopically (Figure 2B). At Day 10 postinjury, six of nine corneas of the Cre-Ad group still showed an epithelial defect or stromal ulceration, whereas only 1/12 corneas treated with BMP-7-Ad showed any defect. At this same timepoint, corneas in both Cre-Ad and BMP-7-Ad groups that remained free of epithelial defects exhibited dense stromal opacification. At Day 20 postinjury, three of the 12 corneas in the Cre-Ad group exhibited epithelial defects/ ulceration and the remaining corneas showed a dense stromal opacification (Figure 2B(c)). In contrast, all corneas in the BMP-7-Ad group exhibited a moderate stromal opacification without epithelial defects (Figure 2B(f)).

Hematoxylin and eosin (HE) staining (Figure 2C) showed that while burned corneas of the Cre-Ad group showed an irregular epithelium and stromal inflammation, such stromal inflammation was less and the epithelial layer was more well-organized in the BMP-7-Ad group at Day 5 (Figure 2C(b,f)). At Day 10, corneas in the Cre-Ad group were characterized by greater inflammation in the stroma and anterior chamber compared to BMP-7-Ad-treated eyes (Figure 2C(c,g)). The absence of staining for keratin 12, which is expressed in corneal, but not conjunctival epithelium, ${ }^{41,42}$ showed that the regenerated epithelium in both Cre-Ad- and BMP-7-Ad- treated groups was of conjunctival origin with the total loss of limbal corneal epithelial stem cells (Saika et al, data in submission 2004). At Day 20, corneas in the Cre-Ad group were, on average, thicker than corneas in the BMP-7-Ad group, which had remodeled to a nearly normal thickness (Figure $2 \mathrm{C}(\mathrm{a}, \mathrm{d}, \mathrm{h}))$; regenerated epithelium contained goblet cells regardless of whether the cornea was treated with Cre-Ad or BMP-7-Ad, although the epithelium remained thicker in the Cre-Ad group (arrows, Figure 2C(e,i)). Stromal inflammation was also less in BMP-7-Ad-treated group corneas as compared with those in the control Cre-AD group (Figure $2 \mathrm{C}(\mathrm{e}, \mathrm{i}))$.

\section{Smad1/5/8 Signaling is Activated and Smad2/3 Signaling is Suppressed in the Injured Cornea by Exogenous BMP-7}

To investigate whether treatment with BMP-7-Ad activates BMP-specific Smad signaling ${ }^{46,47}$ in alkaliburned corneas, cryosections were immunostained with antibodies against phosphorylated Smad1/5/8, as an indicator of activation of $\mathrm{BMP} / \mathrm{Smad}$ signaling. Through Days 5-20 phospho-Smad1/5/8 was readily detected in regenerated epithelium, stromal cells and corneal endothelium of burned corneas treated with BMP-7 Ad (Figure 3A(b,d,f)), whereas almost no immunoreactivity for these Smads was observed 
B

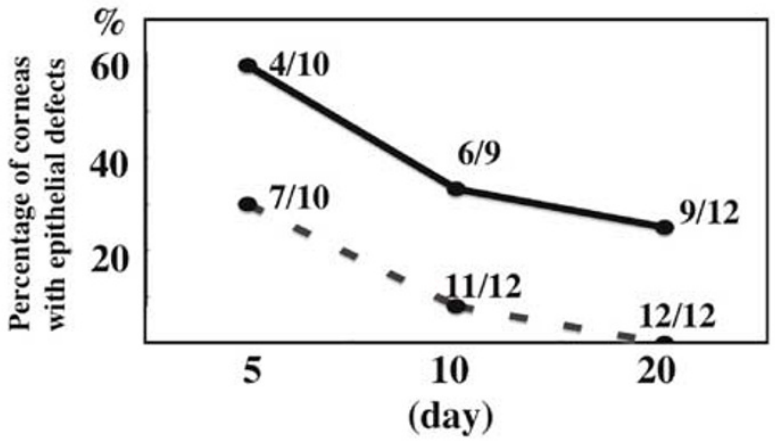

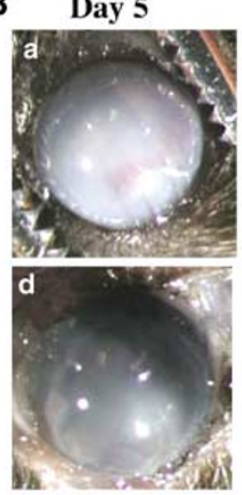

10
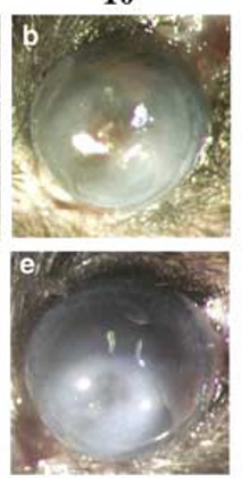

20
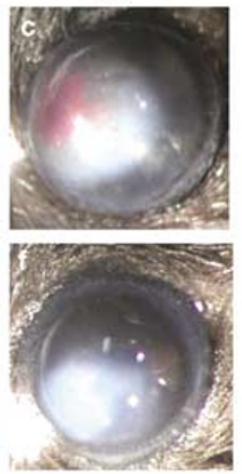
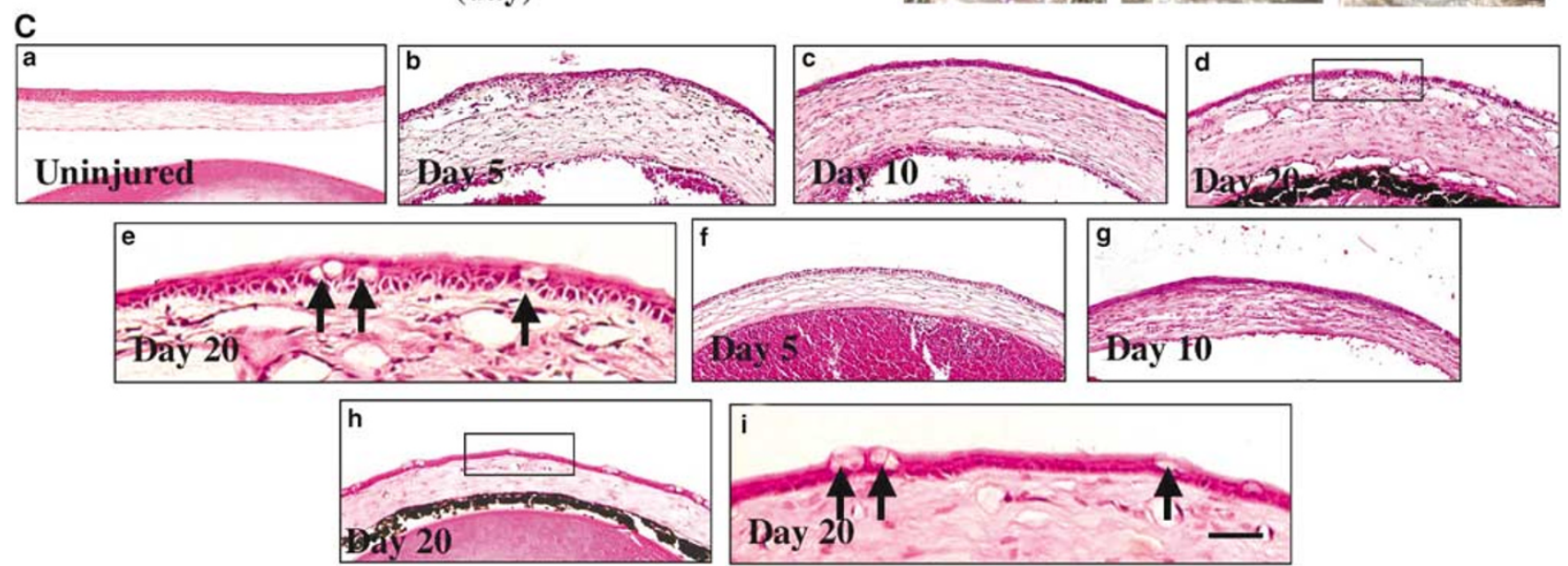

Figure 2 Healing of an alkali-burned mouse cornea treated with either BMP-7-Ad or Cre-Ad. (A) Scoring of the \% incidence of corneas of C57BL/6 mice with an epithelial defect at each timepoint in Cre-Ad (solid line) or BMP-7-Ad-treated (dotted line) groups. (B) Macroscopic observation shows the total ocular surface burn in Cre-Ad-treated (a-c) and BMP-7-Ad-treated mice (d-f) at times from Day 5-20 postinjury. Stromal opacification is less in corneas of BMP-7-Ad group (d-f) as compared with those in Cre-Ad group (a-c). (C) Hematoxylin and eosin staining of burned corneas at indicated times from Day 5-20 postinjury in Cre-Ad-treated (b-e) or BMP-7-Adtreated groups (f-i). Frame a shows an uninjured cornea. Stromal inflammation and edema (as evaluated by the stromal thickness) are less in the corneas of BMP-7-Ad group as compared with those in Cre-Ad control group. At Day 20, higher magnification pictures show the presence of many goblet cells (arrows) in conjunctival epithelium resurfacing the burned corneas in both Cre- Ad (e) and BMP-7-Ad (i) groups. Bar, $100 \mu \mathrm{m}(\mathrm{a}-\mathrm{d}, \mathrm{f}-\mathrm{h}) ; 30 \mu \mathrm{m}$ (e, i).

in Cre-Ad-treated burned corneas (Figure 3A(a,c,e)). As for TGF- $\beta$ /Smad signaling postinjury, phosphoSmad2 was detected in the nuclei of healing epithelium and keratocytes in the paraffin sections of Cre-Ad-treated group (Figure 4B(a,b,e,f)), but to a greatly reduced extent in eyes treated with BMP-7Ad (Figure 3B(c,d,g,h)).

\section{Activation of Keratocytes is Associated with the Poorer Healing in Cre-Ad-Treated Corneas}

One of the well-established hallmarks of scar tissue formation and opacification of corneal stroma is the transdifferentiation of keratocytes into $\alpha$ SMA-positive myofibroblasts. ${ }^{48-51}$ Examination of the expression pattern of $\alpha \mathrm{SMA}$ in injured corneas showed that through Days 5-20 postinjury, many stromal cells in injured corneas of Cre-Ad-treated mice expressed $\alpha \mathrm{SMA}$ (Figure $4 \mathrm{~A}(\mathrm{a}, \mathrm{c}, \mathrm{e})$ ), but that this was substantially reduced in BMP-7-Ad-treated corneas (Figure $4 \mathrm{~A}(\mathrm{~b}, \mathrm{~d}, \mathrm{f})$ ). Keratocyte activation is also associated with upregulation of matrix molecule expression. We therefore examined the mRNA expression of collagen I $\alpha 2$ chain by real-time RTPCR and showed upregulation of col1agen $\alpha 2$ mRNA at Days 10 and 20 in Cre-Ad-treated corneas was markedly suppressed by BMP-7 gene introduction (Figure 4B), further indicating that exogenous BMP7 attenuated keratocyte activation.

Since invasion of monocytes/macrophages plays an important role in tissue damage following injury, including alkali burning in the cornea, ${ }^{52}$ we used the F4/80 antibody to quantify the number of monocytes/macrophages in the central stroma of alkaliinjured corneas (Figure 5A, B). At Days 10 and 20, there was a substantial reduction in the number of F4/80-positive cells in corneas of BMP-7-Ad-treated mice as compared to their respective Cre-Ad controls (Figure 5A, B).

Neovascularization of the corneal stroma likely contributes to stromal opacification and is associated with inflammation. Examination of stromal neovascularization using an antibody to 

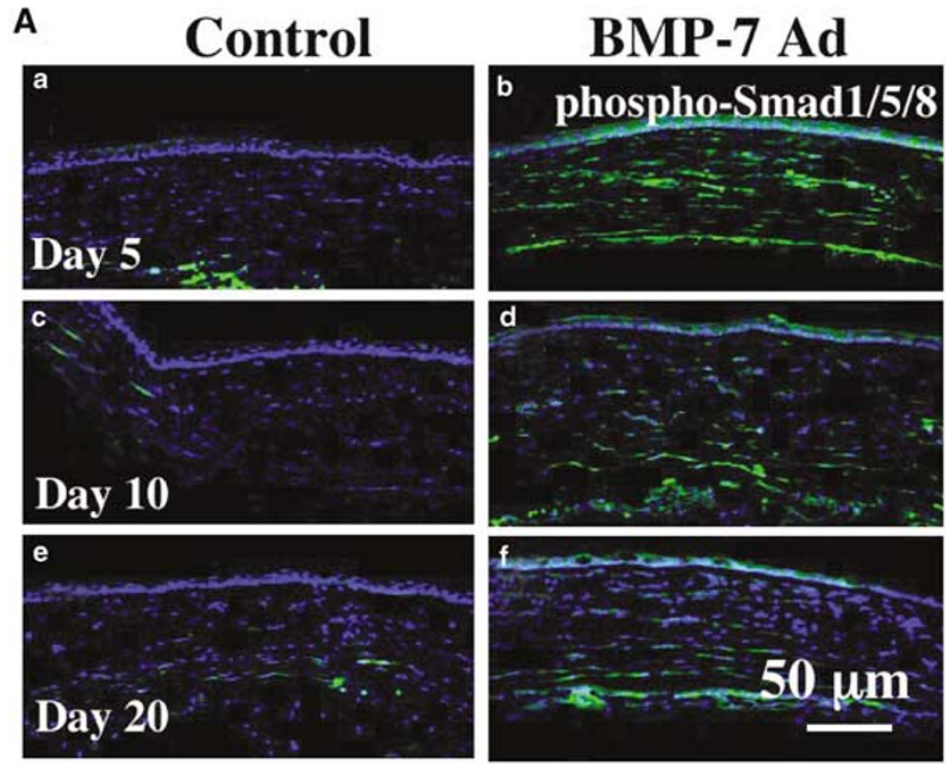

B
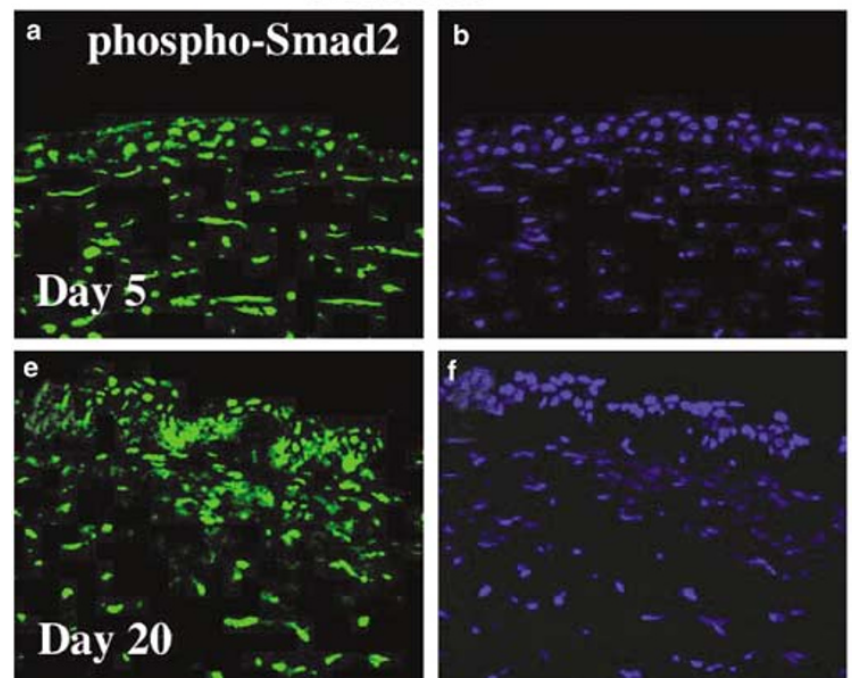
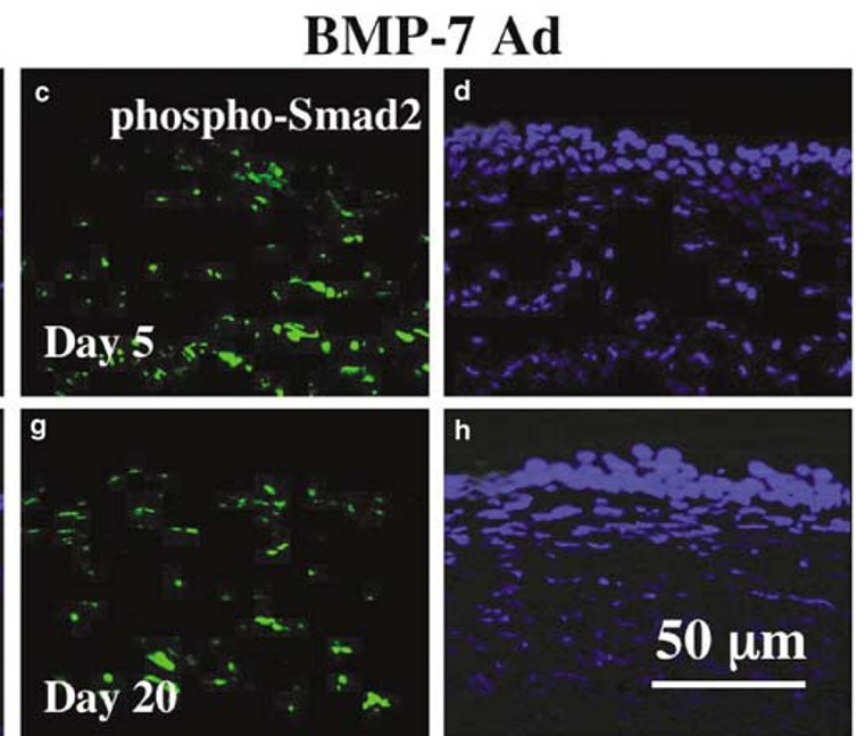

Figure 3 Smad signaling status in alkali-burned corneas treated with Cre-Ad or BMP-7-Ad. (A) Immunofluorescent staining for phosphorylated Smad1/5/8 in corneas treated with either Cre-Ad (a, c, e) or BMP-7-Ad (b, d, f) at Day 5-20 postburn. Phospho-Smad1/5/ 8 is observed in the epithelium, stromal cells, and endothelium BMP-7-Ad-treated corneal at each interval, while it is not, or very faintly, detected in corneas of Cre-Ad group. (B) Immunofluorescent staining for phosphorylated Smad2 in corneas treated with either Cre-Ad (a, e) or BMP-7-Ad (c, g) at Days 5 and 20 postburn. Phospho-Smad2 is readily observed in the epithelium and stromal cells in corneas of Cre-Ad-group at each interval, but it is only faintly detected in healing epithelium of corneas and is detected in the minority of stromal cells in BMP-7-Ad group. Frames b, d, f, and h show DAPI nuclear staining of sections a, c, e and g, respectively. Bar, $50 \mu \mathrm{m}$.

CD31 (PECAM) showed that introduction of BMP-7 did not block stromal neovascularization, although CD31-labeled cells seemed to be slightly less in the corneal stroma of BMP-7-Ad group as compared with control throughout the healing interval (Figure 5C).

Development of corneal ulceration postalklai burn is characterized by degradation of the epithelial basement membrane by MMPs expressed by healing epithelial cells and keratocytes as well as by inflammatory cells. ${ }^{1-7}$ Real-time RT-PCR showed upregulation of MMP-9 in burned corneas during healing and BMP-7's suppression of this MMP-9 upregulation (Figure 6A). We therefore expected that BMP-7 gene introduction might block degradation of epithelial basement membrane in burned corneas during the healing interval. As expected, in the Cre-Ad group immunostaining for type IV collagen showed disruption of the basement membrane and loss of epithelial integrity at each timepoint (Figure 6B(a, $\left.\mathrm{a}^{\prime}\right)$; at Day 10). In contrast, corneas in the BMP-7-Ad group showed a linear 
A
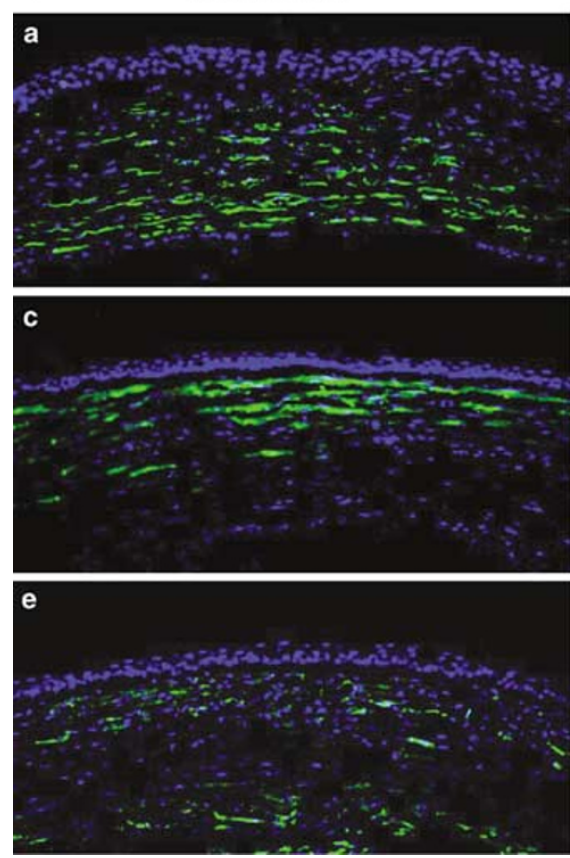

BMP-7 Ad
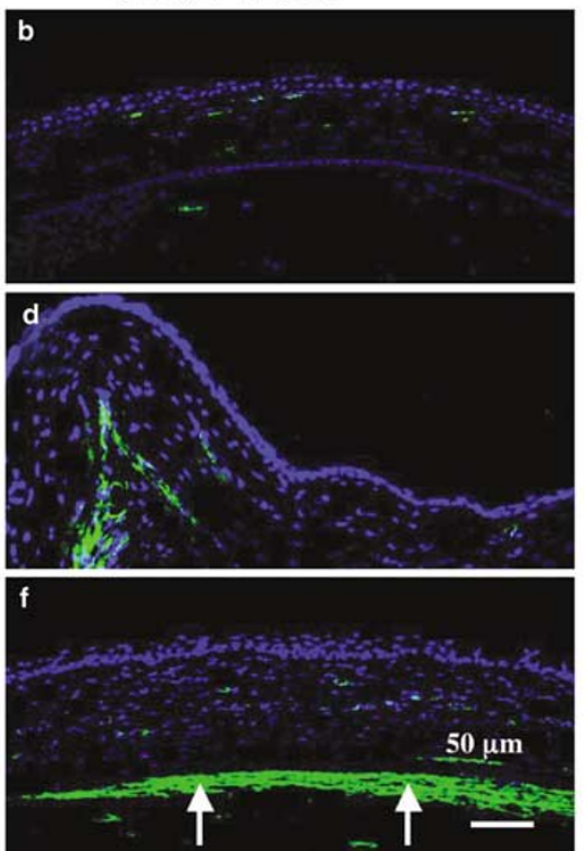

B

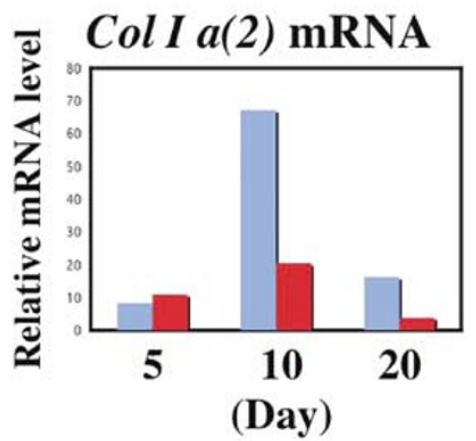

Control

BMP-7 Ad

Figure 4 Analysis of stromal healing in burned corneas. (A) The expression pattern of $\alpha$-smooth muscle actin ( $\alpha$ SMA) as detected by immunofluorescence in stromal cells at Days 5 (a, b), 10 (c, d), and 20 (e, f) postalkali burn of either Cre-Ad (a, c, e) or BMP-7-Ad-treated (b, d, f) mice. At Day 20, iris tissue (arrows) adhered to the corneal endothelium exporess marked $\alpha$ SMA, while corneal stroma is almost free from $\alpha$ SMA-expressing cells. Bar, $50 \mu \mathrm{m}$. (B) Real-time RT-PCR shows marked suppression of collagen I $\alpha 2$ chain mRNA in burned stroma by BMP-7-Ad (red bar) as compared with Cre-Ad-treated cornea (blue bar) at Days 10 and 20. Results typical for repeated measurements.

pattern of subepithelial immunoreactivity indicating an intact basement membrane (Figure $6 \mathrm{~B}\left(\mathrm{~b}, \mathrm{~b}^{\prime}\right)$; at Day 10).

\section{BMP-7-Ad-Treated Corneas Show Reduced Expression of Growth Factors Post-Alkali Injury Compared to Cre-Ad-Treated Controls}

Since various cytokines induced following injury are known to be regulated through TGF- $\beta /$ Smad signaling, we examined the effects of exogenous BMP-7, which antagonizes TGF- $\beta$ signal, on expression of such target genes implicated in the tissue destruction in alkali-burned corneas. It is known that TGF- $\beta 1$ signaling contributes to autoinduction of this growth factor in many injured tissues, and that this results in elevated levels of peptide that typically persist long after the initial injury. MCP-1 is a chemokine which induces chemotaxis of monocytes/macrophages into an injured tissue, and is upregulated by, in part, TGF- $\beta$ signaling. ${ }^{53,54}$ Real-time RT-PCR showed that ectopic BMP-7 expression suppressed upregulation of mRNA expression of TGF- $\beta 1$ and MCP- 1 in healing, burned, corneas at both Days 10 and 20, whereas expression of VEGF mRNA was not reduced at Day 10 (Figure $7 \mathrm{a}-\mathrm{c})$. Immunohistochemical staining in paraffin sections also showed that TGF- $\beta 1$ and 2 were both expressed in the epithelium of the uninjured cornea (Figure $7 \mathrm{~d}$ ). While the level of expression of TGF- $\beta 1$ in epithelium did not change substantially postinjury (data not shown), levels of extracellular TGF$\beta 1$ were significantly elevated at Day 10 (not shown) and persisted at Day 20 postinjury in Cre-Ad-treated eyes (Figure $7 \mathrm{~d}$ ). A similar pattern was observed for TGF- $\beta 2$ and $\beta 3$, with stromal expression of TGF- $\beta 2$ being particularly intense. Overall, the protein expression of TGF- $\beta$ s in the healing stroma was reduced in BMP-7-Ad-treated corneas as compared with control.

BMP-7 Expression Alters the Proliferative Profile of the Healing Epithelium

Cell proliferation in regenerating epithelium is modulated by growth factors/cytokines via autocrine and both paracrine mechanisms. Quantitation of BrdU staining showed that treatment with BMP-7Ad enhanced proliferation of conjunctival epithelium, compared to Cre-Ad-treated eyes at Day 5 (Figure 8A, B).

\section{Discussion}

In the present study, we showed that adenoviral gene transfer of BMP-7 suppresses tissue destruction 

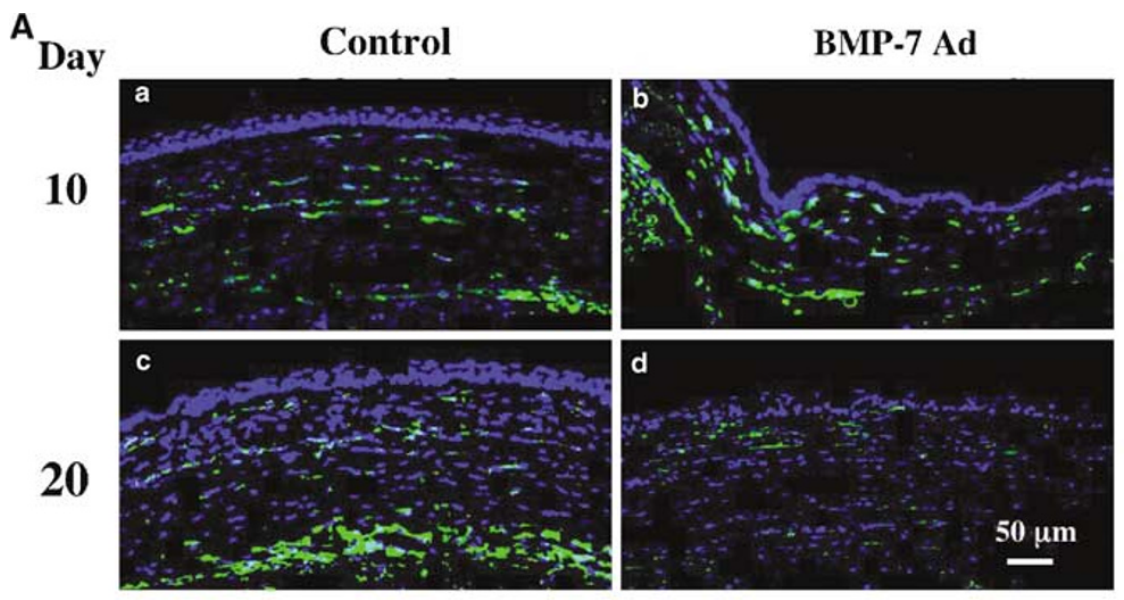

B

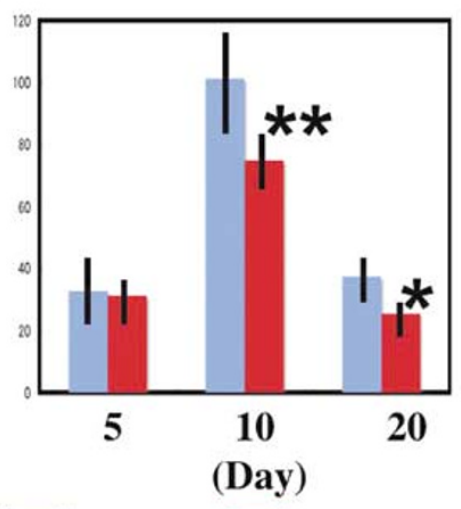

Control $\square$ BMP-7 Ad
C
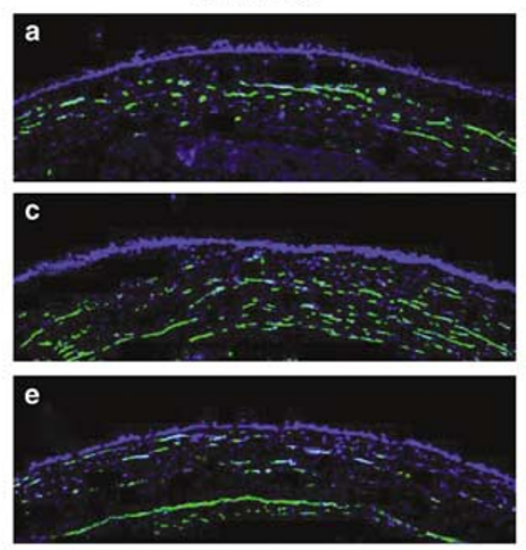

BMP-7 Ad
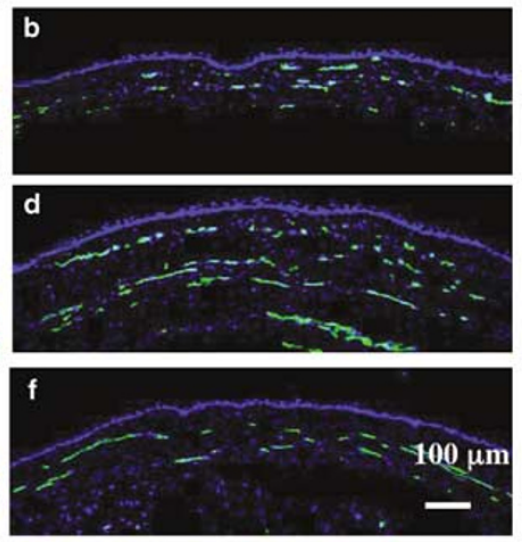

Figure 5 Invasion of monocytes/macrophages and neovascularization in burned corneal stroma. (A) Invasion of monocytes/macrophages into the burned stroma was evaluated by using immunofluorescent staining with F4/80 antibody. BMP-7-Ad treatment reduces the number of F4/80-labeled cells in the central stroma at Days 10 (b) and 20 (d) as compared with control Cre-Ad-treated corneas (a, b). Panel (B) shows bar charts of the number of F4/80-labeled cells determined as described in Materials and methods. There is a statistically significant difference of the numbers of F4/80-positive cells in the central stroma between Cre-Ad-treated control (blue bars) and BMP-7Ad-treated (red bars) groups. ${ }^{* *}$ or * significant as $P<0.01$ or $P<0.05$. (C) Stromal neovascularization as detected by CD31 (PECAM) immunostaining. BMP-7 gene transfer does not seem to reduce stromal neovascularization. Bar, $50 \mu \mathrm{m}(\mathbf{A}) ; 100 \mu \mathrm{m}$ (B).

in a mouse cornea injured with topical alkali application. Burned corneas treated with BMP-7Ad were resurfaced with less scarring as evidenced by restored transparency as compared with control corneas at the final timepoint, Day 20. Conversion of keratocytes to myofibroblasts, as characterized by expression of $\alpha \mathrm{SMA},{ }^{48-51}$ is one of the most important elements of corneal stromal wound healing and is associated with upregulation of matrix components involved in stromal scarring. Although in vitro studies have shown that expression of $\alpha \mathrm{SMA}$ in dermal fibroblasts is regulated by various cytokines and extracellular matrix, that is, fibronectin ED-A, ${ }^{48}$ TGF- $\beta /$ Smad2 signaling is essential for it. $^{55-58}$ In the present study, corneas of the control Cre-Ad group exhibited more prominent myofibroblast generation and delayed re-epithelialization at the final timepoint of Day 20 as compared with those treated with topical BMP-7-Ad. The upregulation of TGF- $\beta$ s in the burned cornea was suppressed by ectopic BMP-7 expression, contributing to its suppression of upregulation of collagen I $\alpha 2$ mRNA expression, as well as decreased incidence of myofibroblast generation in healing stroma. Our immunohistochemical data indicated that the mechanisms whereby overexpression of BMP-7 improves healing of alkali-burned corneas involve attenuating Smad2/3 signaling, which mediates tissue fibrosis, along with upregulation of Smad1/ 5/8 signaling. We have observed that BMP-7 suppresses expression of collagen I $\alpha 2$ mRNA about $25 \%$ in the presence or absence of TGF- $\beta 1$ in primary cultures of human ocular conjunctival fibroblasts (Yamanaka, Saika, Ikeda, 2004, manuscript in preparation), further supporting the in vivo efficacy of BMP-7 gene introduction in inhibiting scarring in an alkali-burned corneas. On the other hand, You and Kruse reported that adding exogenous BMP-7 does not have any effect on $\alpha$ SMA expression in cultured corneal fibroblasts, but TGF- $\beta 1$ stimulated it. They, 
A
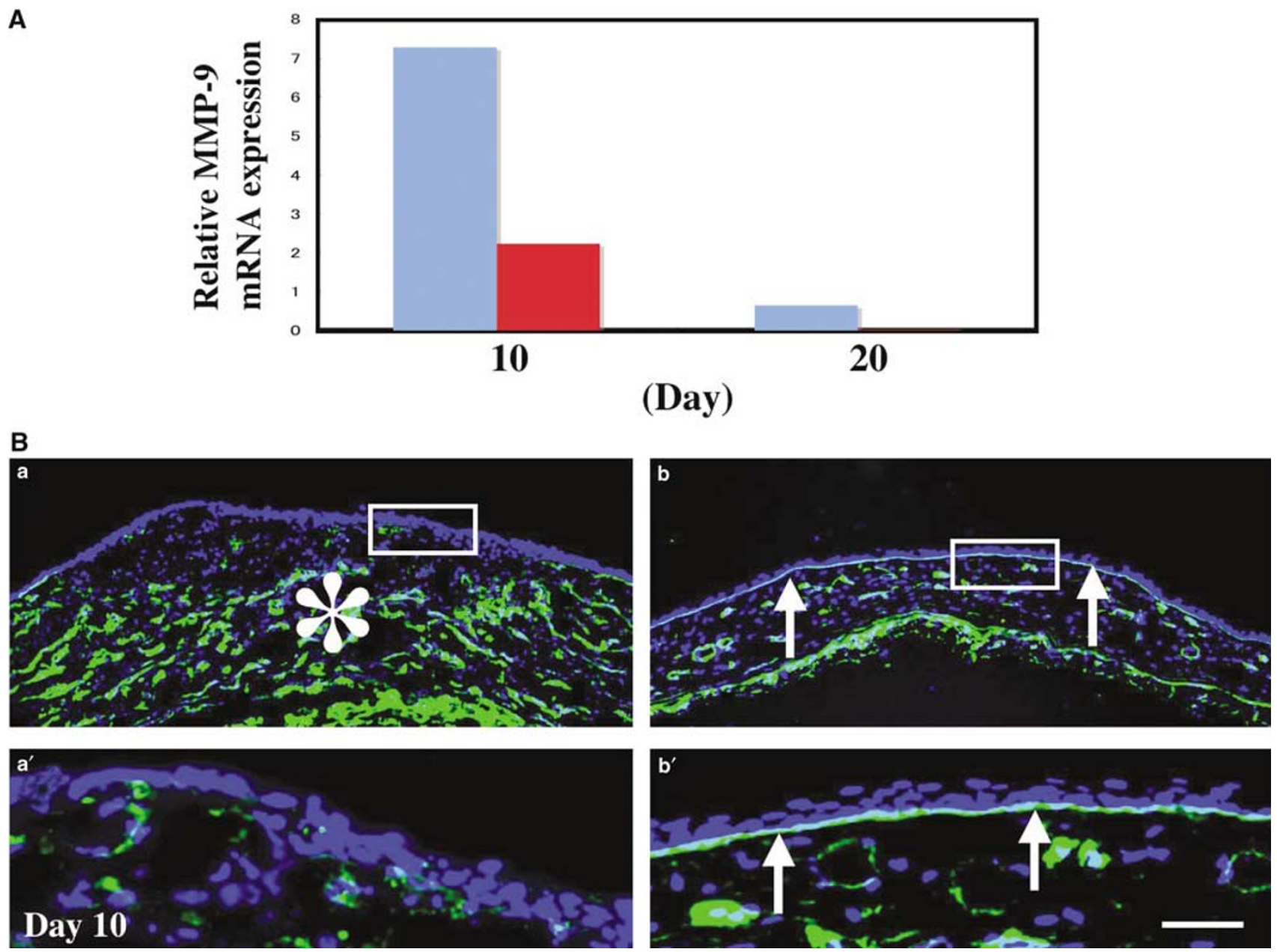

Figure 6 Expression of matrix metalloproteinases-9 (MMP-9) mRNA at Days 10 and 20 (A) and collagen type IV in the cryosections of the burned corneas at Day 10 (B). (A) Upregulation of MMP-9 mRNA in Cre-Ad-treated burned corneas (blue bars) was suppressed by the treatment with BMP-7 Ad (red bars) at Days 10 and 20. (B) Immunofluorescent staining shows the loss of type IV collagen in the epithelial basement membrane region and upregulation in stromal cells (asterisk) in a Cre-Ad-treated cornea (a), whereas liner type IV collagenimmunoreactivity is readily observed in epithelial basement membrane region (arrows) with less expression in the stroma (b). Frames $\mathrm{a}^{\prime}$ and $\mathrm{b}^{\prime}$ indicate the higher magnification pictures of the boxed areas in frames a and $\mathrm{b}$, respectively. Bar, $100 \mu \mathrm{m}(\mathrm{a}, \mathrm{b}) ; 20 \mu \mathrm{m}\left(\mathrm{a}^{\prime}, \mathrm{b}^{\prime}\right)$.

however, did not report on the effect of exogenous BMP-7 on $\alpha$ SMA expression upregulated by TGF- $\beta 1$. Myofibroblast generation in an in vivo alkali-burned cornea is believed to be mainly accelerated by upregulated TGF- $\beta$ (mainly expressed by infiltrated macrophages). In the present experiment, Smad1/5/ 8 signal activated by adenoviral expression of BMP7 is considered to counteract this TGF- $\beta$ 's induction of $\alpha$ SMA.

Since invasion of monocytes/macrophages plays an important role in tissue damage following an injury, such as an alkali burn in the cornea, and their chemotaxis is modulated by TGF- $\beta^{50-52}$ we quantified the number of monocytes/macrophages in the central stroma of alkali-injured corneas treated with BMP-7 gene introduction. As expected, ectopic BMP-7 attenuated invasion of monocytes/macrophages into the burned cornea. This reduction of monocytes/macrophages might result in decreasing the expression of inflammation-related cytokines in burned cornea in addition to the suppression of keratocyte activation by BMP-7. Upregulation of MCP-1 in the burned cornea was suppressed by ectopic BMP-7 gene introduction presumably caused by the reduced invasion of monocytes/ macrophages, which might result in further suppression of invasion of monocytes/macrophages into the healing stroma.

In the present study, ectopic expression of BMP-7 by an adenoviral vector was not sufficient to block alkali burn-induced stromal neovascularization. Since neovascularization of corneal stroma also potentially contributes to opacification, the failure to block stromal neovascularization might be a reason why the ectopic BMP-7 was not as effective as Smad7 adenoviral gene transfer, which completely blocks stromal neovascularization (Saika et al, data in submission 2004). Consistent with this, in our study BMP-7 gene transfer did not block the upregulation of VEGF, the main growth factor 
a

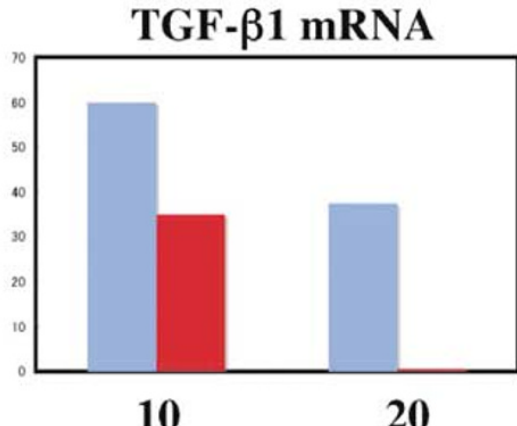

Day

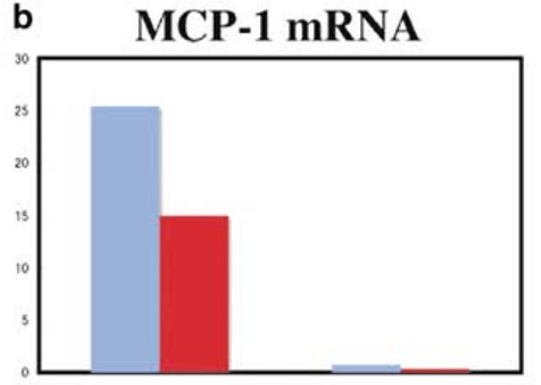

10
20

Day

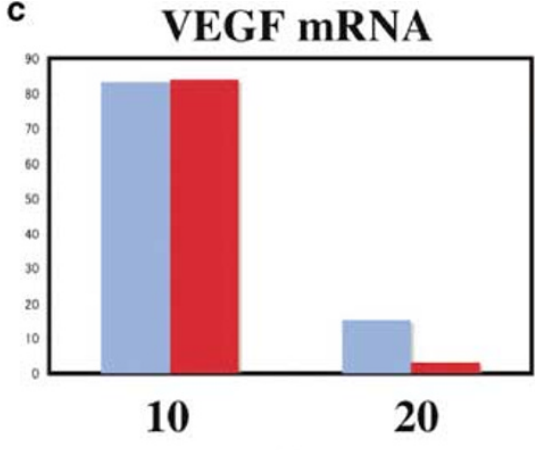

Day

\section{$\square$ Control $\square$ BMP-7 Ad}

d

\section{Control}

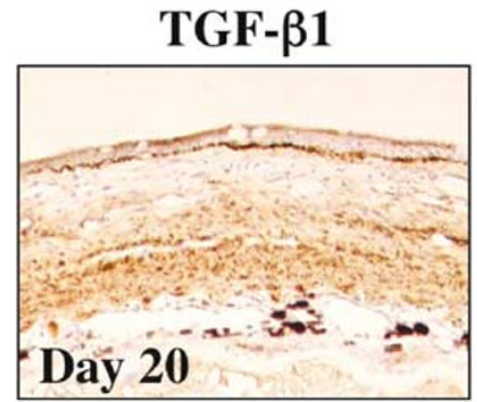

BMP-7 Ad

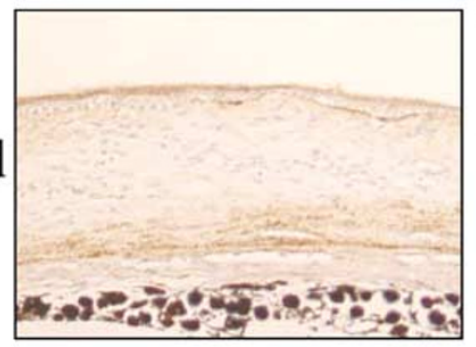

TGF- $\beta 2$
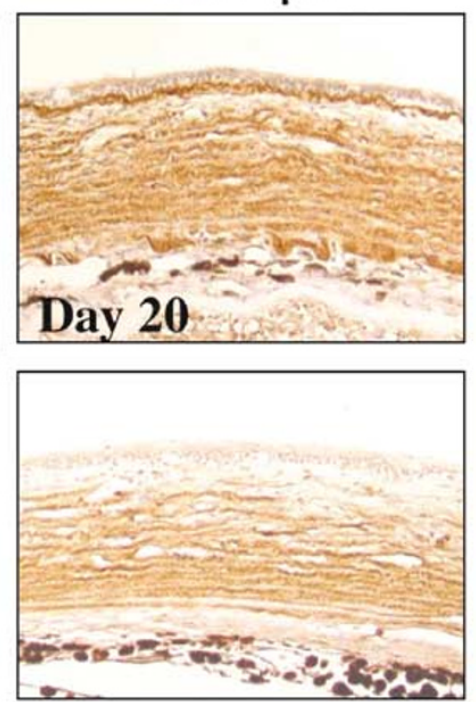

TGF- $\beta 3$
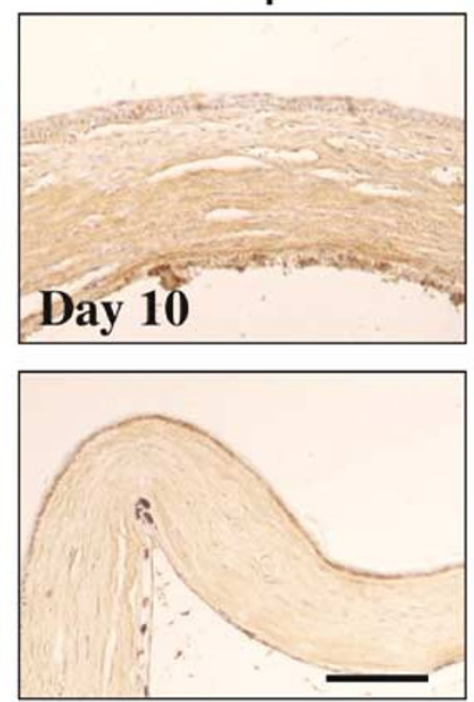

Figure 7 Expression of growth factors in burned corneas. Quantitation of mRNAs of TGF- $\beta 1$ (a), MCP-1 (b), VEGF (c) by real-time RT-PCR at Days 10 and 20 postinjury. The data are shown as relative expression as compared with the expression level in an uninjured cornea. BMP-7-Ad treatment suppresses mRNA expression of TGF- $\beta 1$ or MCP-1 at Days 10 and 20, or 10, respectively. Data represent a typical result in one experiment carried out several times at each timepoint. VEGF mRNA expression is suppressed at Day 20, but not at Day 10. (d) Immunohistochemical detection of extracellular TGF- $\beta 1$ at Day 20 TGF- $\beta 2$ at Day 20 and TGF- $\beta 3$ at Day 10 in representative injured corneas. Overall, BMP-7-Ad-treatment suppresses protein expression of TGF- $\beta$ s in healing stroma. Bar, $100 \mu \mathrm{m}$.

involved in stromal neovascularization in an injured cornea $^{59,60}$ at Day 10, and then suppressed it at Day 20. Reduction of VEGF expression at Day 20 might be attributed to suppressed invasion of monocytes/ macrophages, which are believed to be the main sourse of VEGF. ${ }^{61,62}$

Epithelial healing is also an important component involved in the process of tissue repair of an injured cornea. Cell proliferation in regenerated epithelium is modulated by growth factors/cytokines via complex autocrine and paracrine (derived from stroma) systems. We showed here that exogenous BMP-7 gene expression accelerated cell proliferation in the healing epithelium. As it has been reported that BMP-7 itself does not accelerate cell proliferation in general, such an increase of proliferation potential might be attributed to the reduction of TGF- $\beta$ that normally has a growth-suppressing effect on cells. Moreover, ectopic BMP-7 suppressed both upregulation of MMP-9 in the burned tissue and degradation of epithelial basement membrane in healing, burned, cornea, also explaining the favorable effect of BMP-7 on epithelial regeneration. Similar to our previous report (Saika et al, data in submission 2004), the present study showed that the burned cornea was resurfaced with keratin-12-negative epithelium of conjunctival origin with the total loss of the limbal epithelium. The resurfaced epithelium contained many goblet cells regardless of the treatment, indicating that ectopic BMP-7 was not sufficient for cornea-like transdifferentiation of the conjunctival epithelium. The absence of the conjunctival 

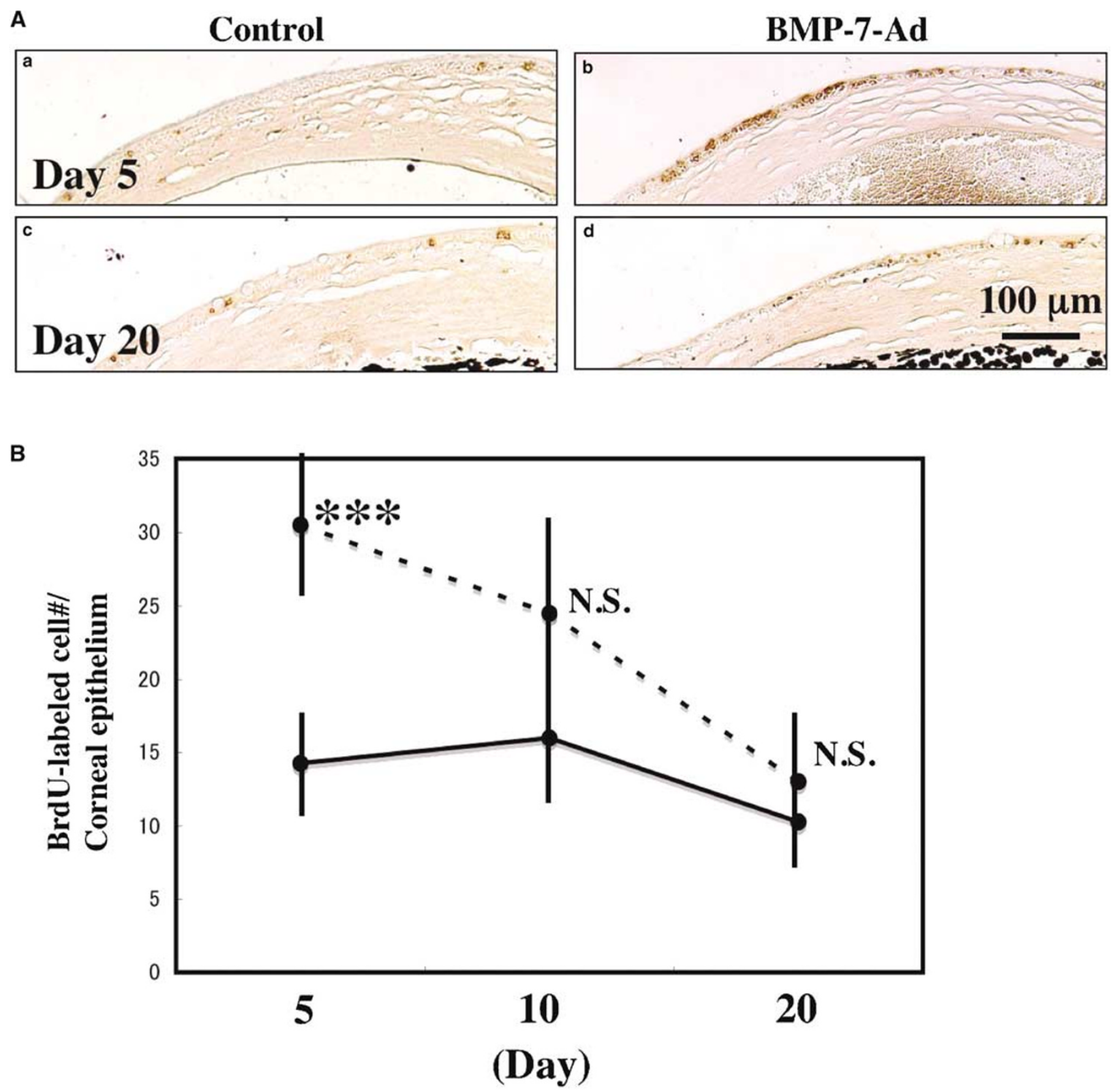

Figure 8 (A) Cell proliferation in healing epithelium as detected by immuno-detection of bromo-deoxyuridine at Days 5 and 20 . Cells with a brown-stained (bromo-deoxyuridine-positive) nuclei are observed in healing epithelia. The incidence of such cells are more frequently detected in a BMP-7-Ad-treated corneas than in a Cre-Ad-treated cornea at Day 5, whereas such a difference is not seen in the specimens at Day 20. Bar $100 \mu \mathrm{m}$. (B) A graph summarizes the incidence of BrdU-labeled cells in healing epithelial at each timepoint. Statistical significance is detected at Day $5\left({ }^{* *} P<0.005\right)$, but not at Days 10 and 20.

transdiffferentiation to cornea-like epithelium might be involved in the reduction of transparency of the healed cornea. It has been reported that this cornea-like transdifferentiation of conjunctival epithelium, which has invaded an injured cornea, requires a reduction of VEGF in the injured tissue. ${ }^{63}$ This report is consistent with our finding that BMP-7 gene introduction did not block stromal neovascularization that is also regulated by local VEGF levels.

\section{Acknowledgements}

This study was supported by a Grant from the Ministry of Education, Science, Sports and Culture of Japan (C15591871 to SS, C16590150 to KI, C15591873 to YO) and Uehara Memorial Foundation (to SS), a Research Grant on Priority Areas from Wakayama Medical University (to SS, YM, and AO), NIH Grant EY 13755, Research to Prevent Blindness, and Ohio Lions Eye Research Foundation (to WW-YK). 


\section{References}

1 Brodovsky SC, McCarty CA, Snibson G, et al. Management of alkali burns: an 11-year retrospective review. Ophthalmology 2000;107:1829-1835.

2 Saika S, Kobata S, Hashizume N, et al. Epithelial basement membrane in alkali-burned corneas in rats. Immunohistochemical study. Cornea 1993;12:383-390.

3 Ishizaki M, Zhu G, Haseba T, et al. Expression of collagen I, smooth muscle $\alpha$-actin, and vimentin during the healing of alkali-burned and lacerated corneas. Invest Ophthalmol Vis Sci 1993;34:3320-3328.

4 Ravanti L, Kahari VM. Matrix metalloproteinases in wound repair. Int J Mol Med 2000;6:391-407 (Review).

5 Ye HQ, Azar DT. Expression of gelatinases A and B, and TIMPs 1 and 2 during corneal wound healing. Invest Ophthalmol Vis Sci 1998;39:913-921.

6 Sivak JM, Fini ME. MMPs in the eye: emerging roles for matrix metalloproteinases in ocular physiology. Prog Retin Eye Res 2002;21:1-14 (Review).

7 Daniels JT, Geerling G, Alexander RA, et al. Temporal and spatial expression of matrix metalloproteinases during wound healing of human corneal tissue. Exp Eye Res 2003;77:653-664.

8 Sridhar MS, Bansal AK, Sangwan VS, et al. Amniotic membrane transplantation in acute chemical and thermal injury. Am J Ophthalmol 2000;130:134-137.

9 Meller D, Pires RT, Mack RJ, et al. Amniotic membrane transplantation for acute chemical or thermal burns. Ophthalmology 2000;107:980-989.

10 Baldwin Jr AS. Series introduction: the transcription factor NF- $\kappa \mathrm{B}$ and human disease. J Clin Invest 2001;107:3-6.

11 Tak PP, Firestein GS. NF- $\kappa$ B: a key role in inflammatory diseases. J Clin Invest 2001;107:7-11.

12 Saika S, Okada Y, Miyamoto T, et al. Role of p38 MAP kinase in regulation of cell migration and proliferation in healing corneal epithelium. Invest Ophthalmol Vis Sci 2004;45:100-109.

13 Andresen JL, Ehlers N. Chemotaxis of human keratocytes is increased by platelet-derived growth factor-BB, epidermal growth factor, transforming growth factoralpha, acidic fibroblast growth factor, insulin-like growth factor-I, and transforming growth factor-beta. Curr Eye Res 1998;17:79-87.

14 You L, Kruse FE. Differential effect of activin A and BMP-7 on myofibroblast differentiation and the role of the Smad signaling pathway. Invest Ophthalmol Vis Sci 2002;43:72-81.

15 Ashcroft GS, Yang X, Glick AB, et al. Mice lacking Smad3 show accelerated wound healing and an impaired local inflammatory response. Nat Cell Biol 1999;1:260-266.

16 Roberts AB, Piek E, Bottinger EP, et al. Is Smad3 a major player in signal transduction pathways leading to fibrogenesis? Chest 2001;120(Suppl):43S-47S.

17 Schnabl B, Kweon YO, Frederick JP, et al. The role of Smad3 in mediating mouse hepatic stellate cell activation. Hepatology 2001;34:89-100.

18 Flanders KC, Sullivan CD, Fujii M, et al. Mice lacking Smad3 are protected against cutaneous injury induced by ionizing radiation. Am J Pathol 2002;160:10571068.

19 Sato M, Muragaki Y, Saika S, et al. Targeted disruption of TGF- $\beta 1 /$ Smad3 signaling protects against renal tubulointerstitial fibrosis induced by unilateral ureteral obstruction. J Clin Invest 2003;112:1486-1494.
20 Flanders KC, Major CD, Arabshahi A, et al. Interference with transforming growth factor-beta/Smad3 signaling results in accelerated healing of wounds in previously irradiated skin. Am J Pathol 2003;163: 2247-2257.

21 Saika S, Kono-Saika S, Ohnishi Y, et al. Smad3 signaling is required for epithelial-mesenchymal transition of lens epithelium after injury. Am J Pathol 2004;164:651-663.

22 Flanders KC. Smad3 as a mediator of the fibrotic response. Int J Exp Pathol 2004;85:47-64 (Review).

23 Bonniaud P, Kolb M, Galt T, et al. Smad3 null mice develop airspace enlargement and are resistant to TGFbeta-mediated pulmonary fibrosis. J Immunol 2004; 173:2099-2108.

24 Saika S, Kono-Saika S, Tanaka T, et al. Smad3 is required for dedifferentiation of retinal pigment epithelium following retinal detachment in mice. Lab Invest 2004;84:1245-1258.

25 Nakao A, Fujii M, Matsumura R, et al. Transient gene transfer and expression of Smad7 prevents bleomycininduced lung fibrosis in mice. J Clin Invest 1999;104: 5-11.

26 Dooley S, Hamzavi J, Breitkopf K, et al. Smad7 prevents activation of hepatic stellate cells and liver fibrosis in rats. Gastroenterology 2003;125:178-191.

27 Dohi M, Hasegawa T, Yamamoto K, et al. Hepatocyte growth factor attenuates collagen accumulation in a murine model of pulmonary fibrosis. Am J Respir Crit Care Med. 2000;162:2302-2307.

$28 \mathrm{Wu} \mathrm{MH}$, Yokozeki H, Takagawa S, et al. Hepatocyte growth factor both prevents and ameliorates the symptoms of dermal sclerosis in a mouse model of scleroderma. Gene Therapy 2004;11:170-180.

29 Klahr S, Morrissey J. Obstructive nephropathy and renal fibrosis: the role of bone morphogenic protein-7 and hepatocyte growth factor. Kidney Int Suppl 2003;87:S105-S112 (Review).

30 Zeisberg M, Bottiglio C, Kumar N, et al. Bone morphogenic protein-7 inhibits progression of chronic renal fibrosis associated with two genetic mouse models. Am J Physiol Renal Physiol. 2003;285: F1060-F1067.

31 Wang S, Hirschberg R. BMP7 antagonizes TGF- $\beta$ dependent fibrogenesis in mesangial cells. Am J Physiol Renal Physiol 2003;284:F1006-F1013.

32 Wang S, Hirschberg R. Bone morphogenetic protein-7 signals opposing transforming growth factor beta in mesangial cells. J Biol Chem 2004;279:23200-23206.

33 Kowanetz M, Valcourt U, Bergstrom R, et al. Id2 and Id3 define the potency of cell proliferation and differentiation responses to transforming growth factor $\beta$ and bone morphogenetic protein. Mol Cell Biol 2004;24:4241-4254.

34 Ruzinova MB, Benezra R. Id proteins in development, cell cycle and cancer. Trend Cell Biol 2003;13: 410-418.

35 Saika S, Ikeda K, Yamanaka O, et al. Transient adenoviral gene transfer of Smad7 prevents injuryinduced epithelial-mesenchymal transition of lens epithelium in mice. Lab Invest 2004;84:1259-1270.

36 Sato Y, Tanaka K, Lee G, et al. Enhanced and specific gene expression via tissue-specific production of Cre recombinase using adenovirus vector. Biochem Biophys Res Commun 1998;244:455-462.

37 Miyake K, Tohyama T, Shimada T. Two-step gene transfer using an adenoviral vector carrying the CD4 
gene and human immunodeficiency viral vectors. Hum Gene Ther 1996;7:2281-2286.

38 Kanegae Y, Miyake S, Sato Y, Lee G, Saito I. Adenovirus vector technology: an efficient method for constructing recombinant adenovirus and on/off switching of gene expression. Acta Paediatr Jpn 1996;38:182-188.

39 Saika S, Shiraishi A, Liu CY, et al. Role of lumican in the corneal epithelium during wound healing. J Biol Chem 2000;275:2607-2612.

40 Saika S, Saika S, Liu CY, et al. TGF $\beta 2$ in corneal morphogenesis during mouse embryonic development. Dev Biol 2001;240:419-432.

41 Kao WW, Liu CY, Converse RL, et al. Keratin 12deficient mice have fragile corneal epithelia. Invest Ophthalmol Vis Sci 1996;37:2572-2584.

42 Moyer PD, Kaufman AH, Zhang Z, et al. Conjunctival epithelial cells can resurface denuded cornea, but do not transdifferentiate to express cornea-specific keratin 12 following removal of limbal epithelium in mouse. Differentiation 1996;60:31-38.

43 Flanders KC, Thompson NL, Cissel DS, et al. Transforming growth factor- $\beta 1$ : histochemical localization with antibodies to different epitopes. J Cell Biol 1989;108:653-660.

44 Flanders KC, Ludecke G, Engels S, et al. Localization and actions of transforming growth factor- $\beta \mathrm{s}$ in the embryonic nervous system. Development 1991;113: 183-191.

45 Tsubota $\mathrm{K}$, Inoue $\mathrm{H}$, Ando $\mathrm{K}$, et al. Adenovirusmediated gene transfer to the ocular surface epithelium. Exp Eye Res 1998;67:531-538.

46 Moustakas A, Pardali K, Gaal A, et al. Mechanisms of TGF- $\beta$ signaling in regulation of cell growth and differentiation. Immunol Lett 2002;82:85-91 (Review).

47 ten Dijke P, Goumans MJ, Itoh F, et al. Regulation of cell proliferation by Smad proteins. J Cell Physiol 2002;191:1-16 (Review).

48 Serini G, Bochaton-Piallat ML, Ropraz P, et al. The fibronectin domain ED-A is crucial for myofibroblastic phenotype induction by transforming growth factorbeta1. J Cell Biol 1998;142:873-881.

49 Tomasek JJ, Gabbiani G, Hinz B, et al. Myofibroblasts and mechano-regulation of connective tissue remodelling. Nat Rev Mol Cell Biol 2002;3: 349-363.

50 Jester JV, Huang J, Petroll WM, et al. TGF $\beta$ induced myofibroblast differentiation of rabbit keratocytes requires synergistic TGF $\beta$, PDGF and integrin signaling. Exp Eye Res 2002;75:645-657.
51 Desmouliere A, Darby IA, Gabbiani G. Normal and pathologic soft tissue remodeling: role of the myofibroblast, with special emphasis on liver and kidney fibrosis. Lab Invest 2003;83:1689-1707.

52 Pfister RR, Haddox JL, Sommers CI. Injection of chemoattractants into normal cornea: a model of inflammation after alkali injury. Invest Ophthalmol Vis Sci 1998;39:1744-1750.

53 Tesch GH, Schwarting A, Kinoshita K, et al. Monocyte chemoattractant protein-1 promotes macrophagemediated tubular injury, but not glomerular injury, in nephrotoxic serum nephritis. J Clin Invest 1999;103: 73-80.

54 Low QE, Drugea IA, Duffner LA, et al. Wound healing in MIP-1alpha(-/-) and MCP-1(-/-) mice. Am J Pathol 2001;159:457-463.

55 Piek E, Ju WJ, Heyer J, et al. Functional characterization of transforming growth factor $\beta$ signaling in Smad2- and Smad3-deficient fibroblasts. J Biol Chem 2001;276:19945-19953.

56 Itoh S, Thorikay M, Kowanetz M, et al. Elucidation of Smad requirement in transforming growth factor- $\beta$ type I receptor-induced responses. J Biol Chem 2003; 278:3751-3761.

57 Yang YC, Piek E, Zavadil J, et al. Hierarchical model of gene regulation by transforming growth factor $\beta$. Proc Natl Acad Sci USA 2003;100:10269-10274.

58 Evans RA, Tian YC, Steadman R, et al. TGF- $\beta 1-$ mediated fibroblast-myofibroblast terminal differentiation-the role of Smad proteins. Exp Cell Res 2003;282: 90-100.

59 Edelman JL, Castro MR, Wen Y. Correlation of VEGF expression by leukocytes with the growth and regression of blood vessels in the rat cornea. Invest Ophthalmol Vis Sci 1999;40:1112-1123.

60 Lai CM, Spilsbury K, Brankov M, et al. Inhibition of corneal neovascularization by recombinant adenovirus mediated antisense VEGF RNA. Exp Eye Res 2002;75: 625-634.

61 Barleon B, Sozzani S, Zhou D, et al. Migration of human monocytes in response to vascular endothelial growth factor (VEGF) is mediated via the VEGF receptor flt-1. Blood 1996;87:3336-3343.

62 Yang ZF, Poon RT, Luo Y, et al. Up-regulation of vascular endothelial growth factor (VEGF) in smallfor-size liver grafts enhances macrophage activities through VEGF receptor 2-dependent pathway. J Immunol 2004;173:2507-2515.

63 Joussen AM, Poulaki V, Mitsiades N, et al. VEGFdependent conjunctivalization of the corneal surface. Invest Ophthalmol Vis Sci 2003;44:117-123. 